\title{
A LUTA EM DEFESA DA EDUCAÇÃO PÚBLICA NO BRASIL (1980-1996): OBSTÁCULOS, DILEMAS E LIÇÕES À LUZ DA HISTÓRIA [LUCELMA BRAGA]
}

\author{
DOI: http://doi.org/10.9771/gmed.v13i3.45517
}

\author{
Marcia Salete Wisniewski Schaly ${ }^{1}$
}

Anita Helena Schlesener ${ }^{2}$

Título: A luta em defesa da educação pública no Brasil (1980-1996): obstáculos, dilemas e lições à luz da história

Autora: Lucelma Braga

Cidade e editora: Marília, Lutas anticapital

Ano de publicação: 2020

Páginas: 369

O presente livro se constituiu a partir da pesquisa de doutoramento da pedagoga Lucelma Silva Braga, que teve o privilégio de ser orientada pelo professor Dr. Dermeval Saviani, que também prefaciou a obra. O percurso de Braga enquanto estudante, professora e pesquisadora é marcado pelo seu interesse singular em temas que se entrelaçam, como educação, hegemonia, política, luta em defesa da educação pública no Brasil, história da educação brasileira, entre outros. Já no mestrado, direcionou seus estudos nesse sentido, produzindo uma dissertação intitulada: "Uma civilização sem alma? Educação e revolução passiva", defendida em 2005. Atualmente, Braga é docente na Universidade Federal do Maranhão.

Se deixar capturar pela leitura desse livro implica apreender a importância da educação pública gratuita, laica e de qualidade para todos os brasileiros. Uma luta de longa data e que não se esgota em defesa da educação pública no Brasil. Nessa linha, a autora buscou compreender como se dá o processo de reorganização da área educacional, debruçando-se sobre questões históricas da revolução burguesa brasileira, desde 1950. A pesquisa abordou três frentes dessa luta pela educação, a saber: “a universalização da educação escolar, a superação do analfabetismo e a reforma da universidade". O objeto de pesquisa - a luta em defesa da educação pública no Brasil - foi abordado pelo método dialético através do materialismo histórico, que o localiza historicamente no desenvolvimento do capitalismo dependente em nosso país, submetido à hegemonia imperialista. A pesquisadora ainda esclareceu que entende a luta em defesa da educação pública como organização de setores da sociedade civil em ações teórico-práticas que se mobilizam no enfrentamento das políticas liberais e neoliberais de ensino definidas pelo Estado Brasileiro.

O livro foi constituído em três capítulos e considerações finais, trazendo na introdução uma breve descrição do estudo realizado.

O primeiro capítulo: “A luta pela educação no Brasil (1957-1984)”, aborda a relação entre educação e capitalismo brasileiro, problematizando as três frentes de luta já mencionadas anteriormente, e que se configuram como questões materializadas no contexto das lutas e mobilizações no desejo de reformas 
estruturais da educação. Nesse capítulo, Braga (2020) contextualiza o capitalismo em desenvolvimento em vários países, situando seu desenvolvimento tardio no Brasil e trazendo aspectos de sua formação social, em especial na relação com a expansão do capital. Para tal, a autora fundamenta-se na teoria marxista e sua análise sobre a sociedade burguesa inglesa, bem como em outros autores como Gramsci.

Braga (2020) analisa a hegemonia imperialista e sua influência no Brasil para exemplificar a "revolução passiva" ou "revolução pelo alto" em nossa sociedade, que sempre foi atualizando o projeto de controle das classes dominantes, mantendo características de uma economia colonialista, assentada na exploração da força de trabalho e na divisão de classes sociais. Tais aspectos são abordados com fundamentação em autores como Caio Prado Jr. (1957) e Florestan Fernandes (1986), que interpretaram a relação e imbricação entre presente e passado na formação econômica, política, cultural e segregação social brasileira. Essa relação entre passado e presente também foi objeto de interesse da pesquisadora, que visou investigar a história da Educação no Brasil e seus entraves nas reformas estruturais à luz das questões que promoveram o golpe empresarial-militar, mantendo o Brasil subordinado ao imperialismo dos EUA e a educação à serviço dessa ideologia.

A partir desse cenário da formação social brasileira, Braga (2020) passa a situar aspectos da historicidade da luta em defesa da educação pública e pela universalização da educação, bem como destaca os movimentos pela reforma universitária que ocorreram no período de 1957 a 1964 - período quando se intensificou a urbanização, a industrialização e o crescimento populacional. Os movimentos da época reivindicavam maior participação das classes trabalhadoras nas decisões políticas, bem como redistribuição da riqueza material e cultural e enfrentamento dos problemas no sistema nacional de educação. Assim, travou-se um longo processo (de 1946 a 1961 quando a Lei 4.024 foi aprovada) na elaboração do anteprojeto da Lei de Diretrizes e Bases da Educação Nacional (LDB). Essa ferramenta legislativa discutia a universalização da educação básica, o problema do analfabetismo e a centralização ou descentralização dos Estados na manutenção da escola pública e gratuita. Educadores importantes fizeram parte dessa luta, entre eles: Anísio Teixeira (1900-1971), que defendia a centralidade da função do Estado no direito à educação para todos; Florestan Fernandes (1920-1995), educador extremamente engajado na luta pela educação pública nas décadas de 1960 a 1990, tendo contribuído para a I Convenção Operária em Defesa da Escola Pública, em 1961; Paulo Freire (1921-1997), grande idealizador da alfabetização de adultos e da educação voltada para as camadas populares e coordenador do Plano Nacional de Alfabetização (no governo João Goulart); e Darcy Ribeiro (1922-1997), Ministro da Educação do Brasil (no governo João Goulart) que realizou profundas reformas, principalmente para erradicar o analfabetismo no país. Destaca-se ainda a participação dos movimentos estudantis como a União Nacional dos Estudantes (UNE) e a criação da Universidade de Brasília na luta pelas reformas na educação.

Nesse capítulo, a autora destaca ainda o que foi chamado de revolução burguesa que defendia os interesses da elite e combatia os movimentos comunistas, manipulando insistentemente a opinião pública, impedindo as reformas nacionais democráticas. Tal movimento deflagrou o golpe empresarial-militar em 1964, direcionando e adequando a transformação brasileira às novas demandas imperialistas e do capitalismo internacional, sob o lema: "segurança e desenvolvimento". Nesses 21 anos de ditadura empresarial-militar, 
leis e decretos foram sendo promulgados com o objetivo de reprimir e controlar a organização da classe trabalhadora e os movimentos de estudantes e intelectuais. Alguns exemplos foram a Lei Antigreve, em1964; a Lei que criou o Fundo de Garantia do Tempo de Serviço (FGTS), em 1966, para favorecer os empresários; o Decreto-Lei 200/67, que direcionou a Reforma Administrativa do Estado aos interesses dos burocratas e empresários, como os das telecomunicações (monopólio da Rede Globo) e das mineradoras (ao custo de massacres e violação dos direitos dos povos indígenas); entre outros.

No campo educacional não foi diferente e, dessa forma, a educação sofreu inúmeras reformas, seja no ensino básico, no secundário e ou no superior, adequando-a ao modelo econômico capitalista e ao projeto de desenvolvimento da ditadura. Tal período foi marcado por ações do Ministério da Educação e Cultura (MEC) em estreita relação com a Agência Norte-americana para o Desenvolvimento Internacional (USAID), de acordo com os interesses e ideologia política do imperialismo estadunidense vinculados à classe dominante brasileira.

Nesse sentido, Braga (2020) vai ressaltar a história da luta em defesa da educação brasileira no período da ditadura, demonstrando a importância que tal luta tem atualmente. As intervenções que o movimento estudantil sofreu, bem como as Universidades (extinção da UNE e ações da chamada “Operação Limpeza”, em 1964, e Atos Institucionais como o AI-5), em especial a UnB, revelam a violência, a repressão, as torturas, as prisões, os massacres e os assassinatos ocorridos contra alunos, professores e intelectuais que lutavam em defesa da Educação pública, gratuita, universal, laica e democrática. Mesmo assim, manteve-se um movimento ativo, mesmo clandestino, em oposição à ditadura.

O período também foi marcado por reformas que incentivaram: crescimento das instituições de ensino privado; mudanças no ensino secundário profissionalizante para as classes populares, aumentando a discriminação e segregação na educação; implantação de cursos de pós-graduações com apoio de iniciativas empresariais para avanço da pesquisa e tecnologia, em especial nas universidades particulares; mudanças curriculares nas universidades, inspirada nas norte-americanas; institucionalização do trabalho infantil para crianças a partir de 12 anos; criação do Movimento Brasileiro de Alfabetização (MOBRAL, 1968); participação ativa da igreja católica no ensino religioso colaborando para o reacionarismo do período ditatorial; entre outras.

No segundo capítulo, intitulado: "Refluxo da contrarrevolução e ascenso dos movimentos de luta em defesa da educação pública: a reorganização do campo educacional na transição prolongada", considerando os longos anos da ditadura empresarial-militar, a autora buscou pensar os seus efeitos, trazendo dados sobre: a pobreza das classes populares e o enriquecimento das classes dominantes (1970); as altas taxas da mortalidade infantil no Brasil e a exploração do trabalho infantil entre 1970 e 1975 (segundo dados do IBGE). Braga (2020) também discute: o aumento considerável do número de crianças entre 7 e 9 anos fora da escola no período de 1973 a 1979; a criação de presídios infantis que utilizavam métodos violentos e funcionavam como escolas especiais; o aumento considerável do custo de vida; a inserção das mulheres, jovens e crianças no mercado de trabalho, entre outros. Além disso, a autora trouxe reflexões sobre as contradições e o processo de reorganização da classe trabalhadora e da área da educação, considerando o surgimento de sindicatos e as mobilizações de educadores e estudantes. 
Ainda nesse capítulo, a autora apresenta, de forma sintética, que a partir de 1970, surgiram a criação de várias entidades associativas, entidades nacionais profissionais, acadêmicas e científicas, demonstrando como essas entidades (Associação Nacional de Pós-Graduação e Pesquisa em Educação ANPEd, Centro de Estudos Educação e Sociedade - CEDES, Associação Nacional de Educação - ANDE) promoveram a realização das Conferências Brasileiras de Educação (CBEs), entre 1980 e 1991. Tais conferências tiveram como marca a condição de aglutinar as forças políticas do campo educacional na luta em defesa da educação pública e democrática.

As CBEs são analisadas de forma minuciosa e crítica por Braga (2020), considerando o contexto histórico-político e contrarrevolução burguesa, cujo cenário fechado impossibilitava as reformas burguesas, seja na área política, agrária, educacional, entre outras. Ela aponta os avanços, dilemas, recuos e entraves na busca pela redemocratização da educação pública até a promulgação da Lei de Diretrizes e Bases em 1996. A autora defende também que a principal dificuldade se encontra na condição capitalista dependente do Brasil porque isso exigiria transformações estruturais nas bases da sociedade, o que não era de interesse da classe burguesa tampouco da chamada "Nova República”.

No terceiro capítulo: “A luta pela educação pública na Constituinte e na LDB (1986-1996)", a autora aborda o trabalho realizado pelas forças políticas das CBEs que deram origem ao Fórum Nacional da Educação o qual, por sua vez, teve papel fundamental na Constituinte e na aprovação da LDB, com a ressalva de que os materiais sobre o Fórum, aos quais teve acesso para sua pesquisa, estavam incompletos, mesmo utilizando várias fontes.

Os Fóruns Nacionais, Estaduais e Municipais tiveram participação ativa nas Comissões de Educação, bem como nas Audiências públicas da Câmera Federal, Câmera de Vereadores e Assembleias Legislativas em defesa da educação pública e, embora tenham avançado em algumas conquistas na Constituição de 1988 e na LDB (1996), não ganharam prioridade para os profissionais da educação e muito menos para as organizações estudantis e demais entidades científicas, que não tiveram garantidos os recursos financeiros que deveriam ser destinados à educação pública. O Fórum marcou sua importância na elaboração das diretrizes educacionais para o Plano Nacional de Educação (PNE), bem como nas propostas que foram incorporadas na Constituição Federal de 1988, em seu capítulo III. Entretanto, nesse contexto, é importante ressaltar que a LDB, em seu texto final (aprovado em 1996), teve perdas consideráveis em função das forças conservadoras, contrárias à escola pública.

A partir da observação e da análise desses movimentos na luta pela defesa da educação pública brasileira, principalmente na trajetória à Nova República, Lucelma Braga tece sua pesquisa, baseando-se nas categorias desenvolvidas por Florestan Fernandes (1920-1995). A autora evidencia as questões políticas em torno da educação, desde 1957 até o momento atual.

Em suas considerações finais, a autora expõe as novas mobilizações a partir de 2017 quando, no governo de Michel Temer, interrompeu-se pelo decreto n 577 a participação das entidades educacionais no FNE/MEC, revogando portarias anteriores dos trabalhos agendados do CONAE (Conferência Nacional de Educação), numa postura antidemocrática. Isso exigiu nova mobilização das entidades educacionais que denunciassem o autoritarismo, criando-se, então, o Fórum Nacional Popular de Educação (FNPE) cuja 
finalidade seria denunciar o autoritarismo desse governo e reivindicar os compromissos com a educação democrática e com o Pano Nacional de Educação. No atual processo de mercantilização e privatização, reflexo de um projeto de ensino domiciliar da educação e estrangulamento das universidades públicas, é fato que a desigualdade social tende a aumentar, excluindo-se estudantes pobres e negros da escola. Tal cenário se mostra agravado pela pandemia do coronavírus, que impôs novos dilemas para a educação pública frente à tendência de transição para o ensino a distância $(\mathrm{EAD})$ e ensino remoto para toda a educação básica.

Para finalizar, consideramos relevantes e imprescindíveis as contribuições dessa obra, através da qual a autora-educadora-militante nos conduz a uma leitura instigante pelo percurso histórico da luta em defesa da educação pública brasileira. As articulações, discussões e análises, numa compreensão dialética da história, contribuem para a contínua luta em defesa da educação, principalmente no cenário político atual em que a extrema direita fascista busca desmontar a educação pública. Assim, recomendamos a leitura para todos os brasileiros comprometidos com essa causa e que acreditam na capacidade de reaglutinar as forças com o objetivo de reconstrução dos Fóruns, como propõe Dermeval Saviani no prefácio do livro, buscando alianças com sindicatos, classe trabalhadora e movimentos em prol da causa social no Brasil. Portanto, superar a fragmentação da luta pela educação é urgente para combater o fascismo e o rumo catastrófico pelo qual estamos sendo deslocados.

\section{Referências:}

BRAGA, L. S. A luta em defesa da educação pública no Brasil (1980-1996): obstáculos, dilemas e lições à luz da história. Marília: Lutas anticapital, 2020.

\footnotetext{
Notas

1 Mestranda em Educação pela Universidade Tuiuti do Paraná (UTP). Graduada em Psicologia (UFPR), especialista em Psicopatologia da infância e adolescência (Sociesc), Magistério de $1^{\circ}$ e $2^{\circ}$ graus (IBPEX) e Psicologia clínica e Psicologia hospitalar (CRP/08). Currículo Lattes: http://lattes.cnpq.br/3291764872316515. Orcid: https://orcid.org/0000-0002-0554-6753. E-mail: marciasws@hotmail.com.

2 Pós-doutora em Educação pela Unicamp. Doutora em História (UFPR) e mestre em Educação (PUC SP). Graduada em Filosofia (UFPR). Pesquisadora do TEPE - Grupo de pesquisa, trabalho educação e políticas educacionais da Universidade Tuiuti (PR).

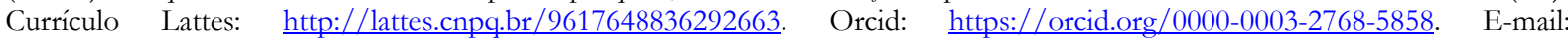
anitahelena1917@gmail.com.
} 